\title{
From bedside to bench: the missing brick for patients with fungal sepsis
}

\author{
Vincenzo Russotto ${ }^{*}$, Andrea Cortegiani, Santi Maurizio Raineri and Antonino Giarratano \\ See related research by Spec et al., http://ccforum.biomedcentral.com/articles/10.1186/s13054-016-1182-z
}

We read with great interest the article by Spec et al. [1] investigating the immunophenotype of $\mathrm{T}$ cells from patients with Candida spp. sepsis. This is the first observational study describing the altered immune response of patients with candidemia. The authors included nonneutropenic critically ill patients with candidemia and non-septic controls, and excluded patients with human immunodeficiency virus infection, who had undergone solid or bone marrow transplantation or with other known causes of impaired immune response. The authors hypothesized that their findings may help explain why patients with fungal sepsis show a high mortality despite appropriate antifungal therapy.

In our opinion, the observed T-cell exhaustion associated with candidemia may also contribute to explain the paradox of the evidence published recently about invasive fungal infection (IFI) prevention [2]. From our recently published Cochrane review [3], the use of antifungals in critically ill patients as untargeted treatment was not associated with any survival benefit despite being associated with a $45 \%$ reduction of IFIs. When prophylactic and empiric antifungal treatments were investigated in sub-analyses, a reduction of IFIs was observed only after prophylactic administration of antifungals. We hypothesized that studies investigating empiric treatment, defined as the administration of antifungals in patients with signs/symptoms of infections at risk for IFIs, included patients with a more advanced disease process, leading to lack of any survival benefit from antifungals. We now may also speculate that poor survival of patients despite untargeted antifungal drugs may depend on their immune status. Patients treated with empiric antifungals may show an impaired immune response, which may play a causative role for reduced survival or may represent a marker of advanced disease process.

Implications for future research may include potential additional mechanisms of impaired immunological function to fill the gap between bedside data and pre-clinical findings.

\section{Abbreviation}

$\mathrm{IFI}$, invasive fungal infection

Funding

The authors did not receive any funding for this article.

Authors' contributions

VR, AC, SMR, and AG conceived the content of the letter. VR and AC wrote the text. All authors read and approved the final version of the manuscript.

\section{Competing interests}

The authors declare that they have no competing interests.

Published online: 21 June 2016

\section{References \\ 1. Spec A, Shindo Y, Burnham C-AD, Wilson S, Ablordeppey EA, Beiter ER, et al. T cells from patients with Candida sepsis display a suppressive immunophenotype. Crit Care. 2015;20(1):1-9. \\ 2. Cortegiani A, Russotto V, Raineri SM, Giarratano A. The paradox of the evidence about invasive fungal infection prevention. Crit Care. 2016;20(1):114. \\ 3. Cortegiani A, Russotto V, Maggiore A, Attanasio M, Naro AR, Raineri SM, et al. Antifungal agents for preventing fungal infections in non-neutropenic critically ill patients. Cochrane Database Syst Rev. 2016;1:CD004920.}

\footnotetext{
* Correspondence: vinrussotto@gmail.com

Department of Biopathology and Medical Biotechnologies (DIBIMED), Section of Anaesthesia, Analgesia, Intensive Care and Emergency, University Hospital Paolo Giaccone, University of Palermo, Via del Vespro 129, 90127 Palermo, Italy
}

(c) 2016 The Author(s). Open Access This article is distributed under the terms of the Creative Commons Attribution 4.0 International License (http://creativecommons.org/licenses/by/4.0/), which permits unrestricted use, distribution, and reproduction in any medium, provided you give appropriate credit to the original author(s) and the source, provide a link to the Creative Commons license, and indicate if changes were made. The Creative Commons Public Domain Dedication waiver (http://creativecommons.org/publicdomain/zero/1.0/) applies to the data made available in this article, unless otherwise stated. 